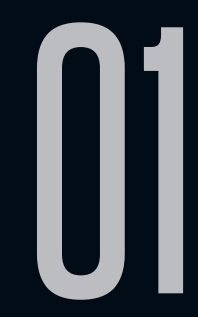

\title{
O GÓTICO, O SUBLIME E A DISTOPIA: UMA LEITURA DE 1984
}

João Pedro Bellas (UFF)

Recebido em 27 ou 2019. João Pedro Bellas é Doutorando em Literatura Aprovado em 18 mai 2020. Comparada pela Universidade Federal Fluminense, com bolsa fomentada pela CAPES e sob orientação do prof. dr. André Cabral de Almeida Cardoso. Possui graduação em Filosofia e mestrado em Literatura Brasileira e Teoria da Literatura pela mesma universidade. Integra o grupo de pesquisa Estudos do Gótico, coordenado pelos profs. drs. Júlio França e Luciana Colucci.

Resumo: Este trabalho tem como principal objetivo refletir sobre uma possível aproximação entre o gótico e a distopia a partir de um estudo do romance 1984, de George Orwell. Apesar das diversas dificuldades existentes em qualquer tentativa de definição de ambos como gêneros discursivos, pretendo delimitar algumas características formais recorrentes tanto em narrativas góticas como naquelas tomadas como distópicas. Com isso em vista, buscarei explorar mais profundamente um elemento específico, a saber, o sublime. No Gótico setecentista, esse conceito estético foi amplamente mobilizado por autores como Matthew Lewis e, principalmente, Ann Radcliffe, tanto como um elemento formal

1 O presente trabalho foi realizado com apoio da Coordenação de Aperfeiçoamento de Pessoal de Nível Superior -Brasil (CAPES) -Código de Financiamento 001. 
para a construção do enredo - especialmente em descrições do espaço narrativo - quanto como um efeito de recepção que se buscava suscitar no leitor. Portanto, pretendo verificar se o sublime é um elemento constitutivo de 1984 para, a partir dele, analisar se é possível descrever o romance de Orwell como uma obra de influxos góticos.

Palavras-chave: Sublime; Gótico; Distopia; 1984, George Orwell.

Abstract: This paper aims at discussing a possible approximation between the gothic and the dystopian literatures based on an analysis of George Orwell's novel 1984. I intend, regardless of the many difficulties in any attempt to define both modes as literary genres, to set out a few formal characteristics recurrent both in Gothic narratives and in those taken as dystopic. With that in mind, a specific element will be explored in greater detail: the sublime. In eighteenth-century Gothic, this aesthetic concept was highly employed by authors such as Matthew Lewis and, especially, Ann Radcliffe, both as a formal device in service of the plot - mainly in spatial descriptions - as well as an emotion to be aroused in the reader. Thus, I intend to examine if the sublime is a constitutive element in 1984 in order to verify if it is possible to describe Orwell's novel as a work influenced by the Gothic.

Keywords: Sublime; Gothic; Dystopia; 1984; George Orwell.

We've taken care of everything The words you read, the songs you sing The pictures that give pleasure to your eyes

It's one for all and all for one We work together, common sons Never need to wonder how or why Rush, "2112" 


\section{INTRODUÇÃO}

As duas vertentes literárias que pretendo discutir e aproximar neste artigo - o gótico e a distopia - assemelham-se, a princípio, por serem de difícil definição e categorização. Desse modo, sem desconsiderar as especificidades dos diversos discursos e teorizações acerca delas, é preciso reconhecer que ambas possuem uma tradição teórica e crítica relativamente extensa e cujos debates não parecem perto de uma conclusão. Tendo isso em vista, talvez o mais prudente seja começar essa empreitada com uma advertência.

Com este artigo, não tenho como objetivo delimitar ou fechar um significado restrito para o gótico e a distopia. Ao contrário, tomarei como base algumas classificações mais instrumentais dessas vertentes literárias que sejam mais profícuas para o que pretendo realizar, isto é, partindo de determinadas noções do que vêm a ser ambas as vertentes, buscarei evidenciar alguns possíveis pontos de contato entre esses dois modos narrativos, tomando como elemento central, mas não exclusivo, o sublime.

Deixo claro, também, que não tenho a pretensão de fazer uma apresentação abrangente das duas vertentes literárias, considerando um corpus ficcional amplo, mesmo porque um estudo dessa natureza demandaria uma investigação mais profunda e extensa do que aquela possibilitada pelos limites espaciais de um artigo. Do mesmo modo, minha proposta não consiste em uma tentativa de dar conta de uma influência do que aqui compreendo como gótico - compreensão esta que será explicitada mais adiante - no gênero distópico como um todo. Assim, não tenho o objetivo de tratar da distopia como um subgênero do gótico no 
século XX (cf. SASSE, 2016) ou, de modo mais radical, afirmar que as narrativas distópicas são narrativas góticas com temporalidades invertidas, projetando no futuro os medos que antes eram situados no passado quase sempre - mas não exclusivamente - medieval. ${ }^{2}$

Considerando que meu objetivo é, antes de qualquer coisa, explicitar algumas possibilidades de aproximação entre os modos narrativos do gótico e da distopia tomando como elemento central o sublime, julguei mais apropriado propor um estudo de caso. Essa proposta é justificada por se tratar de uma abordagem que, por mais restrita que possa parecer, nos permite discutir de maneira mais detalhada as categorias ora em questão, cuja dificuldade de definição já foi mencionada. Nesse sentido, por se tratar de uma obra basilar e bastante influente da distopia, optei por analisar exclusivamente o romance 1984 (1949), de George Orwell. Se minha empreitada for bem-sucedida, diversos elementos tipicamente góticos ficarão evidentes na estrutura da obra, bem como será possível mostrar, de maneira clara, de que modo o uso de uma retórica do sublime pode ser identificado e compreendido em uma narrativa dita distópica, que, à primeira vista, pode parecer completamente oposta a esse conceito estético, relacionado principalmente a ideias de grandiosidade, exaltação e transcendência.

Para a realização de minha proposta, tomarei como principal suporte para compreensão do sublime o tratado de Edmund Burke intitulado Uma investigação filosófica sobre a origem de nossas ideias do sublime e do belo (1757), que constitui, ao lado do tratado grego Peri Hupsous, atribuído a Longino e provavelmente escrito

2 Essa formulação surgiu em uma de minhas inúmeras conversas com o prof. Dr. Júlio França, a quem sou grato pela discussão e esclarecimento de várias das ideias que serão trabalhadas neste texto. 
no século I EC, e da Crítica da faculdade do juízo (1790), de Kant, a tríade de obras mais influentes sobre o sublime da tradição filosófica ocidental. A Investigação de Burke é particularmente interessante para o propósito deste artigo por configurar uma fundamentação filosófica avant la lettre do gótico em função de sua abordagem do sublime, apoiada na ideia de que a experiência descrita por essa categoria estética é calcada principalmente na emoção do terror, ou em ideias que dela seriam derivadas (cf. BOTTING, 1996; PUNTER, 1996; STEVENS, 2000).

Com o objetivo de tornar a minha abordagem mais clara, é pertinente fazer algumas considerações mais gerais sobre o gótico e a maneira segundo a qual ele pode ser relacionado com a distopia. Isso contribuirá, primeiramente, para esclarecer qual compreensão da narrativa gótica servirá de alicerce para a relação que proponho, assim como permitirá evidenciar em que chave de interpretação a distopia será abordada.

\section{O GÓTICO, O SUBLIME E A DISTOPIA}

A distopia, enquanto vertente literária, se consolidou sobretudo a partir da primeira metade do século $X X{ }^{3}$ Keith Booker $(1994$, p.17) sugere que isso se deve principalmente ao contexto da época, marcado pelos horrores de duas grandes guerras, regimes totalitaristas - como a Alemanha nazista, a Itália fascista e a Rússia stalinista - e pela crescente ameaça de um colapso nuclear. Foi nesse período de profundas ansiedades que vieram a lume três 
obras clássicas e essenciais para essa consolidação: Nós (1924), de Yevgeny Zamyatin, Admirável mundo novo (1932), de Aldous Huxley, e 1984, publicado por George Orwell em 1949, pouco tempo depois do fim da Segunda Guerra Mundial.

No que diz respeito ao gótico, o século $X X$ apresenta um contexto de difusão. Fred Botting (1996, p.101), nesse sentido, afirma que, no período novecentista, "o gótico está em toda parte e em parte alguma" ${ }^{\prime \prime}$. Em outras palavras, "gótico" tornou-se um termo guarda-chuva, que designa um fenômeno que, se por um lado é bastante difundido pela cultura, por outro, se apresenta como de difícil apreensão, justamente por se referir a um conjunto de expressões culturais muito amplo e diverso. Inicialmente, tal constatação nos coloca em uma posição um pouco instável naquilo que se refere ao objetivo de propor uma conexão entre a distopia e o gótico. Se, à primeira vista, ela torna quase evidente o fato de que características góticas, por estarem difundidas por toda parte, poderiam se fazer presentes em obras distópicas, ela nos coloca um desafio: tentar compreender de que modo essa presença se manifesta e quais significados ela engendra, de modo que não fiquemos sujeitos a uma leitura superficial dos influxos góticos observados na distopia. Para alcançar esse entendimento, é necessário estabelecer em que termos o conceito de gótico pode ser delimitado.

De modo geral, o gótico não é dos conceitos mais fáceis de se definir, justamente por ser aplicado a coisas bastante diversas entre si. Ele pode fazer referência a um tipo de arquitetura eclesiástica típico da Idade Média, aos povos germânicos que 4 Todas as traduções de obras em língua estrangeira são de minha autoria. 
desempenharam um papel crucial na queda do Império Romano, a uma tendência da moda contemporânea ou a uma literatura cujo objetivo é aterrorizar e prender a atenção do leitor por meio de estratégias ficcionais como o suspense e o mistério (GROOM, 2012, p.xiii). Considerando os objetivos expressos na introdução, é pertinente que nos concentremos nesse último caso.

Há duas maneiras mais recorrentes de compreender o gótico. Podemos utilizar o termo para designar um gênero literário restrito à segunda metade do século XVIII, iniciado com a publicação, em 1764, de $O$ castelo de Otranto, de Horace Walpole, e cujo ápice se deu com autores como Ann Radcliffe e Matthew Lewis no final do período setecentista. Ou podemos tomá-lo como uma poética que descreve um modo narrativo que se consolidou como uma forma de expressar os medos e as ansiedades de diversos grupos sociais, em diversas épocas. Acompanhando Júlio França (2016, p.2492), o que entendo por gótico é "a consubstanciação de uma percepção de mundo desencantada em uma forma artística altamente estetizada, convencionalista e simbólica". Essa compreensão mostra-se mais útil aos propósitos deste artigo, uma vez que ela não se restringe a um estilo de época, descrevendo, ao contrário, um modo discursivo constantemente reelaborado e apropriado para dar conta dos anseios engendrados pela experiência da modernidade.

Um primeiro indício de que a apropriação de elementos góticos é algo comum na distopia é a referência, bastante recorrente, a obras tradicionalmente classificadas como distópicas nos manuais de introdução e nas coletâneas de artigos acadêmicos dedicados ao gótico. Um exemplo é Neuromancer (1984), romance cyberpunk de William Gibson citado por David Punter e Glennis Byron (2004), e 
por Fred Botting (1996), que também analisa obras cinematográficas como Blade Runner (1982), de Ridley Scott, e O exterminador do futuro (1984), de James Cameron. Nesse sentido, cabe a nós analisar em que medida as convenções e símbolos tipicamente góticos são aproveitados pelas distopias, bem como tentar compreender que significado se pretende comunicar ao incorporá-las a uma obra dessa natureza.

Considerando o gótico uma poética, é possível reconhecer alguns traços marcantes - que, eventualmente, se converteram em convenções formais - que se mantêm constantes em obras setecentistas como $O$ monge (1796), de Matthew Lewis, e $O$ italiano (1797), de Ann Radcliffe; do século XIX como Frankenstein (1808), de Mary Shelley, O estranho caso do dr. Jekyll e mr. Hyde (1886), de Robert Stevenson, e Drácula (1897), de Bram Stoker; e também em narrativas do século XX, como Absalão, absalão (1936), de William Faulkner, e A assombração da casa da colina (1959), de Shirley Jackson. Dentre as diversas convenções do gótico, três são mais recorrentes e, provavelmente, mais significativas: o retorno, muitas vezes fantasmagórico, do passado, a personagem monstruosa, e o locus horribilis (cf. FRANÇA, 2016).

Esses elementos, apesar de não serem exclusivos da ficção gótica, configuram, em conjunto, aspectos constitutivos dessa vertente literária desde suas manifestações iniciais, e cumprem o objetivo de dar conta dos medos de um determinado período, sendo, por esse motivo, constantemente repensados e reelaborados com o passar dos anos. Assim, se no século XVIII a ruptura com a Idade Média fez do castelo o locus horribilis dominante e engendrou monstros geralmente ligados a estruturas familiares 
arcaicas - como Manfred, em O castelo de Otranto - ou à corrupção das instituições eclesiásticas, notadamente católicas - como Ambrósio, de O monge; no século XIX a cidade tornouse o principal espaço narrativo do gótico, e as ansiedades que acompanham o progresso científico deram origem a monstros como a criatura de Frankenstein e mr. Hyde, o duplo perverso do dr. Jekyll na novela de Stevenson. O gótico, portanto, apresenta-se como um modo narrativo bastante adequado para que se possa apreender, expressar e compreender os medos de uma época, e sua longevidade é decorrente precisamente desse fato:

O gótico perdurou porque os seus mecanismos simbólicos, particularmente os seus espectros aterrorizantes e assustadores, permitiram-nos lançar muitas das anomalias de nossa condição moderna, mesmo que essas mudem, para espaços antiquados - ou ao menos assombrados - e criaturas extraordinárias. Desse modo, nossas contradições podem ser confrontadas, mesmo que sejam afastadas de nós e projetadas naquilo que é aparentemente irreal, estranho, antigo e grotesco. (HOGLE, 2002, p.6)

No que diz respeito ao modo como esses três elementos são representados, é possível perceber uma predileção pelo sublime. De acordo com Fred Botting, isso é explicado pelo excesso que é, para o teórico, o traço distintivo do gótico:

A ausência de limites, bem como a superornamentação dos estilos góticos, foram parte de um distanciamento das estritas leis estéticas neoclássicas que insistiam na clareza e simetria, na variedade compreendida pela unidade de propósito e desígnio. Gótico significava uma tendência em 
direção a uma estética baseada em sentimento e emoção, e associada primariamente ao sublime. (BOTTING, 1996, p.2)

Sendo, em diversos sentidos, um fruto do século XVIII, a poética gótica surge na esteira de um debate estético mais amplo. Quando, ainda em finais do século XVII, o tratado grego Peri Hupsous - ou Do sublime -, de Longino, foi redescoberto e suas reflexões foram incorporadas como preceitos formais no âmbito do Neoclassicismo, os ideais de clareza e simetria, prezados por esse movimento artístico, passaram a ser, gradativamente, questionados tendo como base o sublime, uma categoria estética associada a ideias anteriormente menosprezadas - ou mesmo ignoradas -, como a grandiosidade, a vastidão e a obscuridade (cf. BELLAS, 2018).

Essa ênfase em ideias antes desprezadas pelos pensadores neoclássicos foi fundamental para o florescimento não apenas do gótico, como também de uma série de manifestações artísticas que privilegiavam a imaginação, o sentimento e as emoções, como a Graveyard Poetry, o movimento alemão Sturm und Drang, capitaneado por Friedrich Schiller e o jovem Goethe, e, posteriormente, o Romantismo. A relação do sublime com o gótico, especificamente, é muito profunda, de modo que a Investigação filosófica de Burke, obra que estabelece de maneira bastante contundente uma separação entre as ideias de belo e sublime, é tradicionalmente tomada como a fundamentação estética e filosófica da literatura gótica. E, de fato, não é mera coincidência que a publicação de $O$ castelo de Otranto tenha ocorrido apenas sete anos após a primeira edição do tratado burkiano. 
As reflexões de Burke são especialmente interessantes para o imaginário gótico por estabelecerem uma conexão explícita e estrita entre a experiência do sublime e sensações de cunho mais negativo, como a dor, o perigo e o terror:

Tudo que seja de algum modo capaz de incitar as ideias de dor e perigo, ou seja, tudo que seja de algum modo terrivel, ou que seja relacionado a objetos terríveis ou que opere de maneira análoga ao terror, é uma fonte do sublime; ou seja, é capaz de produzir a emoção mais intensa que a mente é capaz de sentir. (BURKE, 2018, p.56)

A ênfase no terror e o estabelecimento da obscuridade como um elemento indispensável para tornar qualquer objeto terrível (cf. BURKE, 2018, p.59-60) foram, provavelmente, os principais motivadores do fascínio que suas ideias exerceram sobre os escritores da tradição gótica. E a materialização do pensamento burkiano sobre o sublime no gótico é tão marcante que Nick Groom (2012, p.77-78) destaca sete tipos de obscuridade a figurarem nas obras dessa vertente literária:

1. meteorológico: névoas, ventanias, tempestades, sombras;

2. topográfico: florestas, montanhas;

3. arquitetônico: torres, castelos, tumbas, masmorras, ruínas;

4. material: máscaras, véus, cortinas;

5. textual: folclore, manuscritos ilegíveis, fragmentos, enigmas;

6. espiritual: misticismo, bruxaria, ocultismo.

7. psicológico: sonhos, visões, alucinações.

Considerando a listagem fornecida por Groom, podemos perceber a forma como a obscuridade, e, consequentemente, o 
sublime, são apropriados pelos autores da tradição gótica para descrever o retorno do passado por meio, por exemplo, da figura de fantasmas; para descrever os espaços narrativos, tais como os castelos e, posteriormente, as mansões assombradas, marcados tanto por sua grandiosidade como, quase sempre, por sua decadência, como em Os mistérios de Udolpho, no primeiro caso, ou em A assombração da casa da colina, no segundo; e para compor as personagens monstruosas, muitas vezes veladas e/ou cercadas de mistério, como os próprios fantasmas, mas também assumindo formas desproporcionais, como a criatura de Frankenstein.

No século XX, no entanto, houve um fator determinante para uma guinada no gótico - e, de maneira mais ampla, na narrativa de horror: a eclosão de duas grandes guerras. Como apontado por Bernice Murphy (2016), após a segunda Guerra Mundial, os medos do passado, figurados, por exemplo, nas adaptações cinematográficas da Universal de clássicos góticos como Frankenstein e Drácula, começaram a parecer ultrapassados em um contexto em que ainda se tentava apreender "o fato de que assassinatos em massa haviam ocorrido em uma escala industrial no coração da Europa 'civilizada'” (p.132-133).

Como apontado anteriormente, a distopia consolidouse justamente em meio a esse contexto marcado por duas grandes guerras, potencializado ainda pela ascensão de governos totalitários que se estabeleceram na Europa na primeira metade do novecentos. Isso é especialmente interessante para este artigo na medida em que podemos entender esse estabelecimento da distopia como uma tentativa de dar conta desses novos receios engendrados no período pós-guerra, ou seja, trata-se de um modo 
narrativo cujo objetivo é análogo àquele do gótico. Dessa maneira, é possível vislumbrar as razões que nos permitem aproximar ambas as vertentes ficcionais.

Se, por um lado, a análise do gótico no século XX é dificultada por sua difusão na cultura, por outro, a distopia também se apresenta como algo de difícil apreensão. Isso se deve ao fato de que se trata de uma espécie de texto "impura", já que uma de suas principais características é o "hibridismo textual" (MOYLAN, 2000, p.147). Dessa forma, se é possível perceber em diversas obras distópicas uma filiação a temas caros à ficção científica, o seu tom pessimista quanto à realidade é um indicativo da possibilidade aventada por este artigo, isto é, de que se trata de uma forma textual que guarda uma série de aspectos em comum com o gótico. Contudo, é preciso ressaltar que, por se tratar de um contexto responsável por trazer à tona medos e ansiedades distintos daqueles típicos dos séculos XVIII e XIX, a apropriação de elementos góticos em uma distopia necessariamente implicará a sua transfiguração.

A exemplo do gótico, apesar das dificuldades envolvidas nas tentativas de delimitação conceitual da distopia, alguns traços mais fundamentais mantêm-se constantes. Talvez o aspecto mais fundamental de uma obra dessa natureza seja o fato de se tratar de um texto bastante "carregado politicamente" (MOYLAN, 2000, p.147). Independentemente de representar um regime totalitário, a sociedade de consumo ou os prospectos negativos da cultura de massa, a distopia buscará, de maneira geral, figurar de maneira exacerbada uma situação que se propõe criticar. Nesse sentido, trata-se de uma narrativa que sempre dialoga com o seu tempo: "as sociedades distópicas são geralmente refigurações mais ou 
menos veladas de uma situação que já possui uma existência concreta" (BOOKER, 1994, p.15). Assim, apesar de vislumbrar um futuro distante daquele do autor, a distopia faz, de maneira clara, referência a questões que muitas vezes são bastante concretas. Desse modo, o estado totalitário da Oceânia retratado em 1984, por exemplo, nada mais é do que uma representação de um quadro observado com muita preocupação por George Orwell em seu tempo: a consolidação de regimes totalitários, especialmente a União Soviética stalinista, mas também a Alemanha nazista e a Itália fascista.

Diversos teóricos como Keith Booker (1994) e Maria Varsam (2003) sustentam que essa projeção no futuro faz parte de uma estratégia formal característica da distopia: a desfamiliarização. Essa estratégia está estritamente ligada ao conceito de singularização proposto pelo formalista russo Viktor Chklovski (1976), que defendia que a finalidade da arte era promover e sustentar a percepção dos objetos - cuja visão fora automatizada pelo discurso cotidiano - como se fossem contemplados pela primeira vez:

A principal técnica da distopia é a desfamiliarização: ao focar suas críticas sociais em ambientações distantes no espaço e no tempo, ficções distópicas fornecem perspectivas renovadas a respeito de práticas políticas e sociais que, apesar de problemáticas, poderiam, de outro modo, ser menosprezadas ou consideradas naturais e inevitáveis. (BOOKER, 1994, p.19)

Ainda que não seja exatamente a mesma estratégia formal, esse processo de desfamiliarização operado no interior da distopia 
aproxima-se do gótico na medida em que se imagina uma realidade que, além de deslocada temporalmente, é consideravelmente pior do que a nossa (cf. SARGENT, 1994). Em minha leitura do romance de Orwell, portanto, buscarei evidenciar o modo como uma distopia recorre - mesmo que isso não se dê de maneira intencional - a elementos góticos para potencializar o significado e o alcance da crítica social que pretende empreender, e de que maneira o sublime pode contribuir para isso. Por ter delimitado o retorno do passado, o locus horribilis e a personagem monstruosa como elementos constitutivos de uma narrativa gótica, será sobre eles que irá recair o foco da análise, muito embora uma aproximação do gótico com a distopia não tenha, necessariamente, que ficar restrita a tais componentes.

\section{OS INFLUXOS GÓTICOS DE 1984}

\section{A relação com o passado}

Ao retratar a realidade com um olhar crítico e sob um viés claramente exagerado, a distopia assume um caráter de cautionary tale (cf. BOOKER, 1994), uma vez que busca apontar para as possíveis consequências de um cenário que se apresenta negativo já no presente. Por esse motivo, a distopia contém uma diferença estrutural em relação ao gótico: se este projeta os medos e as ansiedades de uma época no passado, aquela transpõe tais receios para o futuro. Mas, ao contrário do que poderia indicar, isso não quer dizer que o passado é um elemento narrativo completamente irrelevante para uma obra distópica. Considerando especificamente 1984, podemos dizer justamente que o passado ainda desempenha um papel bastante pertinente nessa obra, mesmo que seja 
trabalhado de uma maneira diferente daquela que observamos na ficção gótica mais tradicional.

Podemos identificar, principalmente, duas vias pelas quais o passado se torna significativo para o romance de Orwell. A primeira está relacionada à manipulação exercida pelo Partido sobre o passado, modificando-o constantemente de acordo com os interesses de momento da Oceânia; a segunda é a importância que o passado adquire para Winston, o protagonista da narrativa, como uma forma possível de resistência ao regime totalitário em que ele está inserido.

No que diz respeito à primeira instância, a dominação do passado como uma ferramenta de controle social é expressa de maneira explícita por uma das várias máximas do Partido: "Quem controla o passado controla o futuro; quem controla o presente controla o passado" (ORWELL, 2009, p.47). Em uma narrativa gótica stricto sensu, o retorno fantasmagórico do passado representa um elemento significativo por figurar as ansiedades de uma época que, dado o rápido avanço científico e tecnológico, sofreu uma ruptura repentina com o passado (cf. FRANÇA, 2016). Obscurecido, este se torna uma fonte de incertezas, deixando de ser um meio confiável de se projetar o futuro. Narrativamente, isso é materializado na forma de um crime que havia sido esquecido e retorna no presente com consequências catastróficas. Na distopia, o passado também configura uma fonte de terror, mas - até mesmo por responderem a medos e anseios distintos daqueles dos séculos XVIII e XIX - as razões para isso já não são exatamente as mesmas:

A Oceânia estava em guerra com a Eurásia: em consequência, a Oceânia sempre estivera em 
guerra com a Eurásia. O inimigo do momento sempre representava o mal absoluto, com o resultado óbvio de que todo e qualquer acordo passado ou futuro com ele era impossível.

O assustador, refletiu Winston [...], o assustador era que talvez tudo aquilo fosse verdade. Se o Partido era capaz de meter a mão no passado e afirmar que esta ou aquela ocorrência jamais acontecera - sem dúvida isso era mais aterrorizante do que a mera tortura ou a morte. (ORWELL, 2009, p.47)

Aqui, o que representa um medo maior do que um castigo físico é a possibilidade de o Estado, concretizado na figura do Partido, ter-se tornado tão absoluto a ponto de manipular o passado a bel-prazer, de modo que ele não apenas afirma que algo não aconteceu, mas sim faz com que, para todos os efeitos, determinados eventos nunca tenham de fato ocorrido. Não se trata, portanto, de um evento ancestral esquecido que retorna para assombrar o presente; trata-se de algo que se tornou, ipsis litteris, incognoscível e que, precisamente por esse motivo, pode efetivamente representar qualquer coisa.

Tal maneira de lidar com o passado diz respeito à ameaça de um regime totalitário de se infiltrar tão completamente na realidade a ponto de exercer um controle absoluto sobre ela e, consequentemente, sobre os indivíduos. Essa aspiração a uma dominação irrestrita sobre a vida reflete, como afirmou Hannah Arendt (1989, p.488), "a crença fundamental do totalitarismo de que tudo é possível". No romance de Orwell, essa crença encontra sua forma derradeira no "duplipensamento", em linhas gerais, a habilidade de manter simultaneamente duas ideias contraditórias. Trata-se do instrumento mais bem-acabado para o controle do 
real, já que, com base nele, "o passado, mesmo com sua natureza alterável, jamais fora alterado. Tudo o que fosse verdade agora fora verdade desde sempre" (ORWELL, 2009, p.47).

O passado, portanto, torna-se uma fonte de ansiedade em 1984, por apresentar o registro máximo do domínio totalitário: a sua completa manipulação faz com que ele deixe de ser apenas desconhecido, como era o caso no gótico setecentista; ele passa a configurar uma área de possibilidades quase que ilimitadas e, por essa razão, nunca pode ser verdadeiramente acessado, podendo significar tudo aquilo que o Partido julgar necessário. Esse domínio passa a ser absoluto principalmente por se infiltrar no âmago das pessoas que, sem um contato claro com o seu próprio passado, perdem a sua própria individualidade:

$\mathrm{Na}$ ausência de todo e qualquer registro externo a que recorrer, até mesmo o contorno de sua própria vida perdia a nitidez. A pessoa conseguia evocar os acontecimentos mais notáveis, que muito provavelmente jamais haviam ocorrido. Lembravase de detalhes de incidentes sem conseguir recompor sua atmosfera, e havia longos períodos em branco aos quais não conseguia atribuir fato algum. (ORWELL, 2009, p.44-45, grifo meu)

A instabilidade do passado, constantemente modificado de acordo com os interesses da Oceânia, faz dele algo assustador por concretizar o poder do Partido de se infiltrar integralmente na realidade. Isso estabelece também que o seu verdadeiro conhecimento pode configurar uma possibilidade de resistência ao regime totalitário. Isso se manifesta, principalmente, na fotografia de três líderes revolucionários que, acusados de traição, haviam 
sido executados. Trata-se de um pedaço de jornal que dava conta da presença dos três membros em uma solenidade do Partido em Nova York na mesma data dos supostos crimes que eles haviam confessado. Por representar uma prova cabal da manipulação do passado, a fotografia é vista por Winston como uma ameaça ao regime que o oprime:

Mesmo naquela época, Winston não imaginava que as pessoas varridas da face da Terra nos expurgos haviam efetivamente cometido os crimes de que eram acusadas. Mas [a fotografia] era uma prova concreta; um fragmento do passado abolido, como um osso fóssil que aparece no estrato errado e destrói uma teoria geológica. Bastava para pulverizar o Partido inteiro, se de uma ou outra maneira pudesse ter sido publicado para que o mundo visse e tomasse conhecimento de seu significado. (ORWELL, 2009, p.98)

Ainda que essa possibilidade de resistência não se concretize de maneira efetiva - posteriormente, quando Winston é torturado na parte III do romance, a fotografia é destruída por O’Brien -, ela é significativa para os propósitos da narrativa. Isso porque ela sinaliza a importância do conhecimento do passado para que a ameaça de um regime totalitário não se desenvolva às últimas consequências. Em outras palavras, consciente da ascensão de governos despóticos na primeira metade do século $X X$, Orwell parece ressaltar a importância de uma consciência histórica para evitar que o autoritarismo se espalhe e obtenha o controle sobre a realidade e, por consequência, sobre todos nós.

Ainda que seja trabalhado de uma maneira um pouco distinta da de uma narrativa gótica tradicional, foi possível demonstrar 
que o passado configura um elemento relevante para o enredo distópico de 1984. Nesse aspecto da distopia, contudo, até mesmo por essa diferença estrutural, o sublime não se manifesta tão claramente. O conceito apresenta-se de maneira mais significativa quando nos debruçamos sobre o locus horribilis e a monstruosidade, os outros dois elementos estruturantes do gótico que são ressignificados pela distopia.

\section{O espaço narrativo de 1984}

"Nada existe além de um presente interminável no qual o Partido sempre tem razão" diz Winston a Julia, parceira amorosa do protagonista. Defendi, há pouco, que o passado, em 1984, representa uma fonte de medo por indicar o alcance do poder do Partido de se infiltrar na realidade e a manipular de acordo com seus propósitos e interesses. Essa manipulação articula-se com a constatação de Winston, uma vez que, como atestado pelo lema do Partido mencionado anteriormente, o que possibilita o controle do passado é o controle do presente. Nesse sentido, o que observamos no romance de Orwell é uma estagnação temporal completa: "Em todas as artes úteis, o mundo ou está imóvel ou retrocede" (ORWELL, 2009, p.229). Se há uma ideia de progresso na Oceânia, ela diz respeito apenas à busca por novos meios para cercear a liberdade humana - ou seja, avanços bélicos ou relativos à espionagem.

Esse estancamento temporal é refletido no próprio espaço narrativo de 1984, o que o faz ganhar tintas e contornos marcadamente góticos, sobretudo em seus caracteres decadentes. A Londres fictícia do texto orwelliano é descrita como um lugar em ruínas e coberto 
por poeira e pelas cinzas da constante guerra entre a Oceânia e seu inimigo de momento. Esse ambiente desolado nos é mostrado nos parágrafos iniciais através dos olhos de Winston:

Fora [de seu apartamento], mesmo visto através da vidraça fechada, o mundo parecia frio. Lá embaixo, na rua, pequenos rodamoinhos de vento formavam espirais de poeira e papel picado e, embora o sol brilhasse e o céu fosse de um azul áspero, a impressão que se tinha era de que não havia cor em coisa alguma a não ser nos pôsteres colados por toda parte. (ORWELL, 2009, p.12)

[...] aquela era Londres, principal cidade da Faixa Aérea Um, terceira mais populosa das províncias da Oceânia. Tentou localizar alguma lembrança de infância que lhe dissesse se Londres sempre fora assim. Será que sempre houvera aquele cenário de casas do século XIX caindo aos pedaços, paredes laterais escoradas com vigas de madeira, janelas remendadas com papelão, telhados reforçados com chapas de ferro corrugado, decrépitos muros de jardins adernando em todas as direções? E os lugares bombardeados, onde o pó de gesso dançava no ar e a salgueirinha crescia e se espalhava sobre as pilhas de entulho? $\mathrm{E}$ os locais onde as bombas haviam aberto clareiras maiores e onde tinham brotado colônias sórdidas de cabanas de madeira que mais pareciam galinheiros? (p.13-14)

As passagens acima evidenciam como um tipo de descrição tipicamente gótico é apropriado - mesmo que isso não represente uma influência direta ou mesmo consciente - por Orwell. Aqui, o campo semântico é sobrecarregado de matizes sombrios e de degradação. Além da evidência de que se trata de uma cidade estagnada no tempo - as habitações datam do século XIX -, 
a Londres de 1984 é caracterizada por sua decadência, algo marcado textualmente tanto pelos vestígios de guerra quanto pelos indícios de deterioração material, como o excesso de poeira pela cidade, os remendos improvisados nas casas e a quase completa ausência de cores.

Esse cenário incolor e frio é de especial importância para o funcionamento do romance, pois ele cumpre a função de marcar o estado de espírito vivenciado por Winston e, é possível inferir, de todos os habitantes de Oceânia. Isso é importante porque um dos alvos da crítica ao totalitarismo feita em 1984 é o perigo de que toda individualidade seja perdida frente à ubiquidade do regime totalitário. Nesse sentido, o que se observaria seria uma massa uniforme de seres humanos, sem qualquer traço que permitisse distinguir os indivíduos. No romance, nos deparamos com um regime que, em certa medida, já alcançou esse objetivo. Por esse motivo, toda marca de vida - metaforicamente, de cor - refere-se ao próprio Partido; só o que se destaca em meio à poeira londrina são os pôsteres, que a todo momento relembram a vigilância constante do Grande Irmão, e os enormes prédios dos ministérios.

Os quatro ministérios da Oceânia, além de representarem por si sós um exercício de duplipensamento - o da Verdade é encarregado da manipulação dos fatos, o do Amor cuida da tortura, o da Paz é voltado para a guerra, e o da Pujança fica a cargo do racionamento de suprimentos -, compõem os braços de poder do Partido, e os seus prédios refletem toda a sua grandiosidade. Nesse sentido, a retórica do sublime é amplamente explorada: 
luz direta, pareciam tão temíveis [grim] quanto as seteiras de uma fortaleza. O coração de Winston se encolheu diante do enorme vulto [shape] piramidal. O edifício era forte demais, não havia como tomá-lo. Nem mil bombas-foguetes seriam capazes de destruí-lo. (ORWELL, 2009, p.39)

A passagem evidencia a exploração de duas ideias, a infinitude e a obscuridade, essenciais para a produção de um sentimento de terror, fonte do sublime de acordo com o modelo descrito por Edmund Burke. Apesar de não haver, na realidade concreta, nenhum objeto verdadeiramente infinito, aqueles que, por sua vastidão, inviabilizem a apreensão de seus limites são capazes de preencher a mente humana por um sentimento de terror (BURKE, 1990, p.67). Isso se dá porque, frente a tais objetos, somos confrontados pela percepção das limitações de nossas faculdades. Daí a resposta emocional de Winston à contemplação do prédio do Ministério da Verdade cuja magnitude é marcada pelas incontáveis janelas que se estendem para além da vista. O medo experimentado pelo protagonista é potencializado pelo acréscimo da obscuridade à cena, que faz com que a estrutura arquitetônica em questão se assemelhe a uma fortaleza, sinalizando inclusive o seu caráter indestrutível, atestando, por extensão, o poder e a indestrutibilidade do próprio Partido.

Enquanto um efeito estético, talvez seja possível afirmar que o sublime não se concretiza na narrativa de 1984, uma vez que não há uma virada do desprazer ocasionado pelo sentimento de terror para o deleite que acompanharia uma experiência do sublime (cf. BURKE, 2018, p.56). Entretanto, o seu uso formal cumpre um importante papel dentro da retórica hiperbólica que caracteriza 
uma distopia. Pensando especificamente no romance de George Orwell, a utilização do sublime como uma ferramenta formal cumpre a tarefa de assinalar o status alcançado pelo Estado totalitário da Oceânia: o poder e o alcance do Partido tornaram-se tão grandes que ele se elevou para além dos indivíduos; o Partido tornou-se uma estrutura virtualmente ubíqua e, para todos os efeitos, transcendeu a realidade física. Isso nos leva ao terceiro ponto que me propus a analisar nessa aproximação da distopia com o gótico.

\section{O Estado como monstro}

Quando pensamos no gótico, um dos seus elementos mais notáveis é a personagem monstruosa. Mesmo não sendo exclusiva da narrativa gótica, a monstruosidade é um componente que lhe é essencial e, embora o passado e o locus horribilis cumpram um importante papel nessa vertente ficcional, são os monstros que corporificam substancialmente os medos e ansiedades de uma época (cf. COHEN, 2000), e o gótico é responsável por fixar e tornar icônicas no imaginário ocidental personagens como a criatura de Frankenstein, Drácula e mr. Hyde. Na distopia, por outro lado, de uma maneira geral, é difícil pensar em um monstro corporificado. Ainda que representem figuras que detêm uma posição de poder, indivíduos como o capitão Beatty, de Fahrenheit 451, o comandante Waterford, de O conto da aia e o próprio O’Brien de 1984 são apenas parte de uma estrutura muito mais ampla. Nesse sentido, se pensarmos no modo como a distopia se apropria desse elemento do gótico, podemos constatar que se trata, no caso do romance de Orwell, do próprio Estado totalitário, concretizado não em uma pessoa, mas no Partido. 
Vimos anteriormente como o prédio do Ministério da Verdade, um dos braços do poder do Partido, é capaz de inspirar um grande temor em Winston. A força que aquela construção representa, contudo, é apenas uma amostra do real alcance do Estado totalitário descrito por Orwell. Como indiquei anteriormente, o Partido, com o seu poder em constante crescimento, configura uma estrutura virtualmente onipresente, gerando um clima perene de paranoia, marcado, entre outras coisas, pela presença das teletelas, capazes de captar a mínima alteração no semblante de uma pessoa:

Não havia como saber se você estava sendo observado num momento específico. Tentar adivinhar o sistema utilizado pela Polícia das Ideias para conectar-se a cada aparelho individual ou a frequência com que o fazia não passava de especulação. Era possível inclusive que ela controlasse todo mundo o tempo todo. Fosse como fosse, uma coisa era certa: tinha meios de conectarse a seu aparelho sempre que quisesse. Você era obrigado a viver - e vivia, em decorrência do hábito transformado em instinto - acreditando que todo som que fizesse seria ouvido e, se a escuridão não fosse completa, todo movimento examinado meticulosamente. (ORWELL, 2009, p.13)

A vigilância ininterrupta exercida sobre as pessoas, na verdade, reflete a principal ameaça do totalitarismo identificada por George Orwell: a possibilidade de um cerceamento absoluto da liberdade humana que teria como consequência a obliteração do indivíduo. Em última instância, o objetivo do Partido é alcançar o máximo de poder possível, como confessa O’Brien a Winston em uma das várias sessões de tortura descritas na parte III do romance: "O Partido deseja o poder exclusivamente em benefício próprio. Não 
estamos interessados no bem dos outros; só nos interessa o poder em si" (ORWELL, 2009, p.307). A percepção do Partido, atestada por O’Brien, é a de que, para alcançar esse poder total, é necessário abolir o indivíduo:

Sozinho - livre - o ser humano sempre será derrotado. Assim tem de ser, porque todo ser humano está condenado a morrer, o que é o maior de todos os fracassos. Mas se ele atingir a submissão total e completa, se conseguir abandonar sua própria identidade, se conseguir fundir-se com o Partido a ponto de ser o Partido, então será todo poderoso e imortal. A segunda coisa que você deve entender é que poder é poder sobre os seres humanos. Sobre os corpos - mas, acima de tudo, sobre as mentes. Poder sobre a matéria - a realidade objetiva, como você diria não é importante. Nosso controle sobre a matéria já é absoluto. (ORWELL, 2009, p.309, grifo meu)

O abandono da identidade, essencial para o sucesso da empreitada do Partido, implica a recusa da própria humanidade. A extinção da individualidade significa a redução da humanidade ao papel de mera engrenagem em uma estrutura maior, ou apenas uma célula em um organismo, de acordo com a metáfora empregada por O’Brien (cf. ORWELL, 2009, p.308). Nesse sentido, o sublime apresenta-se como um conceito relevante para que possamos entender esse elemento essencial para a narrativa de 1984.

Desde os primeiros discursos sobre o sublime, foi percebido que se trata de uma experiência que envolve uma perda momentânea da própria subjetividade. O conceito quase sempre é relacionado com a noção de êxtase - ou sua contraparte religiosa, o arrebatamento -, que descreve o estado quando a 
pessoa está fora de si. Nesse sentido, os objetos tradicionalmente tomados como sublimes - o oceano, as montanhas, as grandes construções arquitetônicas - são aqueles capazes de inspirar, momentaneamente, um sentimento de perda da subjetividade que culmina em uma experiência de exaltação. Nesses termos, o que o Partido almeja é tornar-se o objeto sublime por excelência, na medida em que abarcaria todas as pessoas, gerando uma massa uniforme e, assim, eliminando - já não apenas momentaneamente - a percepção da subjetividade, como O’Brien revela a Winston:

Não pense que se salvará, Winston, por mais absoluta que seja a sua rendição. Ninguém que tenha se desencaminhado foi poupado. E mesmo que resolvêssemos deixá-lo viver até o fim de seus dias, mesmo assim você jamais escaparia de nós. 0 que lhe acontecer aqui é para sempre. Tenha isso em mente desde já. Nós o esmagaremos, deixaremos você num estado do qual não há retorno. Vão Ihe suceder coisas das quais você não poderia se recuperar nem se vivesse mil anos. Nunca mais lhe será possível ter sentimentos humanos comuns. Tudo estará morto dentro de você. Nunca mais lhe será possível experimentar o amor, a amizade, a alegria de viver, o riso, a curiosidade, a coragem ou a integridade. Ficará oco. Vamos espremê-lo até deixá-lo vazio, e depois o preencheremos conosco mesmos. (ORWELL, 2009, p.300, grifo meu)

Isso é percebido pelo próprio Winston enquanto, ao escrever em seu diário, reflete sobre as condições da Oceânia:

O ideal definido pelo Partido era uma coisa imensa, terrível e luminosa - um mundo de aço e concreto cheio de máquinas monstruosas e armas aterrorizantes - , uma nação de guerreiros 
e fanáticos avançando em perfeita sincronia, todos pensando os mesmos pensamentos e bradando os mesmos slogans, perpetuamente trabalhando, lutando, triunfando, perseguindo - trezentos milhões de pessoas de rostos iguais. (ORWELL, 2009, p.93)

A principal marca da monstruosidade do Partido consiste, portanto, nessa ameaça à individualidade. Não por acaso, Keith Booker (1994, p.71), em sua análise do romance, identifica a ideologia do Partido à visão de mundo típica de uma religião: "Assim como em muitas religiões convencionais, a solidariedade partidária é promovida por rituais de comunhão". A principal diferença é que a lógica desses rituais, baseados geralmente numa ênfase no amor - especialmente em religiões cristãs - é invertida por Orwell na medida em que o principal ritual do Partido é um evento chamado "Dois Minutos de Ódio". A comparação estabelecida por Booker corrobora a leitura que proponho, uma vez que o sublime é um conceito que, em larga escala, seculariza uma experiência antes monopolizada por rituais religiosos. Assim, em 1984, o sublime configura um elemento formal relevante também porque permite estabelecer o Partido como essa entidade que transcende o indivíduo, e cujo poder, como venho ressaltando, é capaz de manipular a realidade concreta bem como a própria mente e as emoções das pessoas.

\section{CONSIDERAÇÕES FINAIS}

A leitura que propus da obra de George Orwell explicita algumas características que a distopia compartilha com o gótico. Mesmo que a relação entre essas duas vertentes literárias possa 
ser explorada por outras perspectivas, a análise que empreendi esclarece de que forma elementos centrais da ficção gótica podem ser apropriados e retrabalhados de modo a ganhar novos significados no interior de uma narrativa distópica.

A interpretação dessa ressignificação de elementos como o passado, o locus horribilis e da própria personagem monstruosa, permite também uma maior compreensão da estrutura formal da distopia, sobretudo, nesse caso, de 1984. Por se tratar de um modo discursivo marcado por uma percepção de mundo pessimista, que visa a criticar e/ou satirizar, por meio de uma construção hiperbólica, situações que se apresentam como negativas na realidade concreta, a distopia encontra na poética gótica um conjunto de estratégias e recursos bastante profícuo para dar conta dos medos e ansiedades com os quais procura lidar.

\section{REFERÊNCIAS}

ARENDT, Hannah (1989). As origens do totalitarismo. Roberto Raposo (Trad.). São Paulo: Companhia das Letras.

BELLAS, João Pedro (2018). A busca pela transcendência nos trópicos: o sublime no Romantismo brasileiro. 106f. (Dissertação - Mestrado em Literatura Brasileira e Teoria da Literatura). Instituto de Letras, Universidade Federal Fluminense, Niterói. BOOKER, M. Keith (1994). The dystopian impulse in modern literature: fiction as social criticism. Westport: Greenwood Press.

BOTTING, Fred (1996). Gothic. The New Critical Idiom. London: Routledge.

BURKE, Edmund (1990). A philosophical enquiry into the origin of our ideas of the sublime and beautiful. New York: Oxford University Press.

(2018). "Uma investigação filosófica sobre a origem de nossas ideias do sublime e do belo (fragmentos)". João Pedro Bellas (Trad.). In: FRANÇA, Júlio e ARAÚJO, Ana Paula (Orgs.). As artes do mal: textos seminais. Rio de Janeiro: Bonecker. p.52-60. 
CHKLÓVSKI, Viktor (1976). “A arte como procedimento". In: TOLEDO, Dionísio de Oliveira (Org.). Teoria da literatura: formalistas russos. 3.ed. Porto Alegre: Editora Globo. p.39-56.

CLAEYS, Gregory (2017). Dystopia: a natural history. Oxford: Oxford University Press. COHEN, Jeffrey Jerome et al (2000). Pedagogia dos monstros: os prazeres e os perigos da confusão de fronteiras. Tomaz Tadeu da Silva (Trad.). Belo Horizonte: Autêntica.

FRANÇA, Júlio (2016). "O gótico e o retorno fantasmagórico do passado". In: Anais do XV Encontro ABRALIC. Rio de Janeiro: Dialogarts. p.2492-2502.

GROOM, Nick (2012). The gothic: a very short introduction. Oxford: Oxford University Press.

HOGLE, Jerrold E (2002). "Introduction: the Gothic in western culture". In: (Ed.). The Cambridge companion to gothic fiction. Cambridge: Cambridge University Press. p.1-20.

MOYLAN, Tom (2000). Scraps of the untainted sky: science fiction, utopia, dystopia. Boulder (CO); Oxford (UK): Westview.

MURPHY, Bernice M (2016). "Horror fiction from the decline of Universal horror to the rise of the psycho killer". In: REYES, Xavier Aldana (Ed.). Horror: a literary history. London: The British Library. p.131-157.

ORWELL, George (2000). Nineteen eighty-four. London: Penguin. (2009). 1984. Alexandre Hubner e Heloísa Jahn (Trad.). São Paulo: Companhia das Letras.

PUNTER, David (1996). The literature of terror: a history of gothic fictions from 1756 to the present day, Vol.1. London: Longman.

PUNTER, David \& BYRON, Glennis (2004). The Gothic. Blackwell Guides to Literature. Oxford: Blackwell.

SARGENT, Lyman Tower (1994). "The three faces of utopianism revisited". Utopian Studies, 5(1), 1-37.

SASSE, Pedro (2016). "Um vilão chamado progresso: distopia e gótico em Não verás país nenhum". In: Anais do III Congresso Internacional Vertentes do Insólito Ficcional. Rio de Janeiro: Dialogarts. p.709-732. 
STEVENS, David (2000). The gothic tradition. Cambridge: Cambridge University Press.

VARSAM, Maria (2003). "Concrete dystopia: slavery and its others". In: BACCOLINI, Raffaella; MOYLAN, Tom (Orgs.). Dark horizons: science fiction and the dystopian imagination. New York: Routledge. p.203-224. 